\title{
Effect of reducing total fat intake on body weight: systematic review and meta-analysis of randomised controlled trials and cohort studies
}

\author{
(®) $(1)$ OPEN ACCESS
}

\author{
Lee Hooper senior lecturer in research synthesis and nutrition ${ }^{1}$, Asmaa Abdelhamid research \\ associate $^{1}$, Helen J Moore research associate ${ }^{2}$, Wayne Douthwaite research associate ${ }^{2}$, C Murray \\ Skeaff professor ${ }^{3}$, Carolyn D Summerbell professor of human nutrition ${ }^{2}$
}

${ }^{1}$ Norwich Medical School, University of East Anglia, Norwich NR4 7TJ, UK; ${ }^{2}$ Obesity Related Behaviours Group, School of Medicine and Health, Wolfson Research Institute, Durham University, Stockton on Tees, UK; ${ }^{3}$ Department of Human Nutrition, University of Otago, Dunedin, New Zealand

\begin{abstract}
Objective To investigate the relation between total fat intake and body weight in adults and children.

Design Systematic review and meta-analysis of randomised controlled trials and cohort studies.

Data sources Medline, Embase, CINAHL, and the Cochrane Central Register of Controlled Trials to June 2010.

Inclusion criteria Randomised controlled trials and cohort studies of adults or children that compared lower versus usual total fat intake and assessed the effects on measures of body fatness (body weight, body mass index, or waist circumference) after at least six months (randomised controlled trials) or one year (in cohorts). Randomised controlled trials with any intention to reduce weight in participants or confounded by additional medical or lifestyle interventions were excluded.
\end{abstract}

Data extraction Data were extracted and validity was assessed independently and in duplicate. Random effects meta-analyses, subgroups, sensitivity analyses, and metaregression were done.

Results 33 randomised controlled trials (73 589 participants) and 10 cohort studies were included, all from developed countries. Meta-analysis of data from the trials suggested that diets lower in total fat were associated with lower relative body weight (by $1.6 \mathrm{~kg}, 95 \%$ confidence interval -2.0 to $-1.2 \mathrm{~kg}, I^{2}=75 \%, 57735$ participants). Lower weight gain in the low fat arm compared with the control arm was consistent across trials, but the size of the effect varied. Metaregression suggested that greater reduction in total fat intake and lower baseline fat intake were associated with greater relative weight loss, explaining most of the heterogeneity. The significant effect of a low fat diet on weight was not lost in sensitivity analyses (including removing trials that expended greater time and attention on low fat groups). Lower total fat intake also led to lower body mass index $\left(-0.51 \mathrm{~kg} / \mathrm{m}^{2}, 95 \%\right.$ confidence interval -0.76 to -0.26 , nine trials, $\mathrm{I}^{2}=77 \%$ ) and waist circumference (by $0.3 \mathrm{~cm}$, $95 \%$ confidence interval -0.58 to $-0.02,15671$ women, one trial). There was no suggestion of negative effects on other cardiovascular risk factors (lipid levels or blood pressure). GRADE assessment suggested high quality evidence for the relation between total fat intake and body weight in adults. Only one randomised controlled trial and three cohort studies were found in children and young people, but these confirmed a positive relation between total fat intake and weight gain.

Conclusions There is high quality, consistent evidence that reduction of total fat intake has been achieved in large numbers of both healthy and at risk trial participants over many years. Lower total fat intake leads to small but statistically significant and clinically meaningful, sustained reductions in body weight in adults in studies with baseline fat intakes of $28-43 \%$ of energy intake and durations from six months to over eight years. Evidence supports a similar effect in children and young people.

\section{Introduction}

The optimal intake of total fat was debated at the Joint Food and Agriculture Organization of the United Nations/World Health Organization expert consultation on fats and fatty acids in human nutrition held in November 2008. It was agreed that any effect of total fat intake on body weight was crucial to making global recommendations (in the context of increasing overweight and obesity, in particular in low and middle income countries undergoing rapid transition in nutrition). Overweight and obesity increase the risk of many cancers, coronary heart disease, and stroke. ${ }^{1-3}$

Although a previous systematic review found no randomised controlled trials of lower total fat intake that aimed to assess 
effects on body weight, ${ }^{4}$ metaregression within a systematic review assessing randomised controlled trials on the effects of step I and II diets (diets designed by the National Heart Lung and Blood Institute national cholesterol education programme to reduce the risk of cardiovascular disease in the general public and those at increased cardiovascular risk, respectively), found a strong relation between total fat intake and body weight. ${ }^{5}$ That review, however, included studies of as short as three weeks' duration and studies in which weight loss was a goal of the intervention, which may have overstated any relation because advice was to lower both fat and energy intake, and it excluded many trials of reduction in total fat intake that did not fit the step I or II criteria.

To understand the relation between total fat intake and body weight, WHO requested the WHO Nutrition Guidance Expert Advisory Group (NUGAG) subgroup on diet and health (www. who.int/nutrition/topics/NUGAG_meeting/en/index.html) to assess the relation with a view to updating WHO guidelines on total fat intake. To fulfill the requirements of the development process for the new guideline, a systematic review was needed of all available evidence of longer term effects of total fat intake on body fatness, in studies not intending that participants lose weight. WHO therefore commissioned a systematic review and meta-analysis to assess the relation between total fat intake and indicators of body fatness (including obesity, waist circumference, and body mass index) using all appropriate randomised controlled trials and cohort studies in adults and children. The expert advisory group aimed to generate a recommendation on the population impact of total fat intake in the development of obesity. The group agreed that populations recruited specifically for weight loss studies and interventions intended to result in weight loss would be excluded. This was because they were potentially confounded by the implicit objective of reducing calorie intake to produce weight loss and would therefore lead to an overemphasis on studies carried out in highly selected obese populations in North America and Europe, which may have limited application to non-obese populations or those in developing countries or in countries in transition.

\section{Methods}

We followed the methods of the Cochrane Collaboration, with a view to development of WHO guidance according to WHO's process for the development of guidelines. ${ }^{67}$

We included randomised controlled trials and prospective cohort studies in apparently healthy children or adults from any country. Randomised controlled trials had to compare an intervention intended to reduce total fat intake by reducing percentage energy from fat or total fat in $\mathrm{g} / \mathrm{day}$ with a usual fat intake arm and to continue the intervention for at least 26 weeks. The intervention could include dietary advice or provision of foods or whole diet but should not be confounded by effects of other lifestyle or medical interventions. We included studies where a low fat diet was compared with usual diet, or a low fat diet plus any non-dietary intervention was compared with usual diet plus the same non-dietary intervention, but we excluded studies where a low fat diet plus any non-dietary intervention was compared with usual diet alone. Studies of interventions where weight loss was intended (in either or both arms or in any proportion of participants) were excluded. Some measure of body fatness (body weight, body mass index, or waist circumference) had to be assessed as change from baseline or at study end. Cohort studies had to assess the relation between total fat intake at baseline and change in a measure of body fatness from baseline over at least one year, or body fatness at least a year later.

\section{Study identification}

We ran two independent searches to June 2010. The first search through Medline, Embase (both on OvidSP), and the Cochrane Central Register of Controlled Trials focused on randomised controlled trials in adults (see supplementary table $1 \mathrm{a}^{8}$ ). The other search through Medline, Embase, and CINAHL focused on randomised controlled trials and cohort studies in adults and children (see supplementary table $1 b^{9}$ ). Neither search was limited by language. For further trials we checked the bibliography of a related systematic review. ${ }^{10} \mathrm{We}$ also asked members of the NUGAG subgroup on diet and health for relevant local studies, and six regional offices of WHO sent official letters to member states to solicit relevant studies carried out in their countries.

\section{Study assessment}

For each search we independently assessed the titles and abstracts and determined the eligibility of full text papers for inclusion (each independently and in duplicate). We also independently and in duplicate extracted data and assessed the validity of the studies. Differences between the reviewers were resolved by discussion and, if necessary, in consultation with a third reviewer. The reviewers attempted to contact authors of randomised controlled trials to retrieve missing data on study validity but not on outcome data or for cohort studies owing to limitations on time.

For randomised controlled trials we extracted data on participants, interventions, outcomes (body weight, body mass index, and waist circumference) and characteristics of trial quality. Where possible we also collected data on potential effect modifiers, including health status; cardiovascular risk; age; sex; country; baseline body mass index; mean years in trial; number of participants randomised and analysed; type of comparison; total and saturated fat intake during intervention period; energy, carbohydrate, sugar, protein, and alcohol intake; baseline total fat intake; information on intention to treat analyses; and difference in total fat intake (as a percentage of energy) between randomised arms at the latest time point. For dichotomous outcomes in each randomised arm we extracted the number of participants experiencing an outcome and total number of participants randomised. For continuous outcomes we extracted the number of participants assessed and the means and standard deviations of the change in, or final readings of, each treatment arm; where data were available on both change and final readings we used the data on change. Data were extracted at the latest time point within 6-11 months, 12-23 months, 24-59 months, and 60 or more months.

For cohort studies we collected data on setting, design, measurement of the exposure to total fat, characteristics of the participants, similarity at baseline between high and low fat exposure groups, participant flow, and endpoint criteria. We also collected any assessment of the relation between outcome (body weight, body mass index, or waist circumference) and total fat intake, and the most adjusted and any non-energy adjusted assessments.

\section{Assessment of validity}

For the randomised controlled trials we used the Cochrane criteria ${ }^{6}$ to examine study validity, including sequence generation; allocation concealment; blinding of participants, staff, and outcome assessors; incomplete outcome data; and 
selective outcome reporting. Additional review specific criteria included presence or not of dietary interventions over and above alteration of total dietary fat, and similarity or not of type and intensity of intervention in both arms.

For cohort studies we used the Newcastle-Ottawa criteria ${ }^{11}$ modified after consideration of the crucial factors for this review. These criteria included whether the design used a control group that was chosen from the collated cohort (internal) or chosen as a separate group (external); number lost to follow-up; baseline similarity of the most and least exposed groups; factors adjusted for in analysis; and method of assessment of total fat intake. Moderate risk of bias was suggested where less than $20 \%$ were lost to follow-up, up to two major factors were unadjusted for in the design or analysis, and diet was assessed using a 24 hour recall or diet diary: all other studies were at high risk of bias.

\section{Data analysis}

Where $\mathrm{P}<0.05$ we considered the results to be statistically significant. To assess mean differences in outcome between lower and higher fat intake arms for randomised controlled trials we combined the data by the inverse variance method in random effects meta-analysis in Review Manager version 5.0 (Nordic Cochrane Centre, Cochrane Collaboration, 2008). Where there was more than one relevant intervention arm but only one control arm we pooled the intervention arms to create a single pairwise comparison. ${ }^{6}$ We excluded intervention arms not appropriate for this review or that were less appropriate than other arms. When two arms were appropriate for different subgroups then we used the control group once with each intervention arm, but we did not pool the subgroups overall. When outcomes were assessed at more than one time point, for general analyses we used data from the latest time point available, but all relevant time points were used in subgroups by study duration. We used the $\mathrm{I}^{2}$ test to examine heterogeneity, with more than $50 \%$ heterogeneity considered to be important. ${ }^{6}{ }^{12}$ The possibility of publication bias was examined by funnel plots. $^{13} 14$

Prespecified subgroupings included mean follow-up time, difference in fat intake between intervention and control groups (dose effect, difference of up to 5\% of energy from fat, $>5 \%$ to $10 \%,>10 \%$ to $15 \%$, and $>15 \%$ ), total fat intake of control group, year results were first published, and sex. After discussion of the preliminary results with the NUGAG subgroup on diet and health at its second meeting in March 2011, we added the following subgroupings for randomised controlled trials in adults: difference in level of attention given to participants in intervention and control arms, goal for percentage of energy from total fat in intervention arm, intervention resulted in more or less than $30 \%$ energy from fat, and baseline body mass index (mean $<25, \geq 25$ to 29.9 , and $\geq 30$ weight $(\mathrm{kg}) /\left(\right.$ height $\left.(\mathrm{m})^{2}\right)$ ). A difference in the level of attention given to the intervention and control groups meant any variation, including any difference in the amount of health professional or training time or number or timing or duration of follow-ups. Journal referees requested that subgroupings by health status (healthy people not recruited on the basis of health status, those with risk factors such as high lipid levels or breast cancer risk, and current illness such as diabetes, coronary heart disease, cancer, or intestinal polyps) and by degree of energy reduction in the low fat group compared with the control or usual fat group were added. The NUGAG subgroup on diet and health also requested metaregression, which was run in STATA/IC 11.2 to assess the effects of study duration, amount of reduction in total fat in the intervention arm compared with the control arm (as percentage of energy), and fat intake in the control group as subgrouping suggested that these factors may relate to degree of weight loss (multiple regression model, all three assessed together). Finally, the NUGAG subgroup on diet and health requested that data on serum lipid levels and blood pressure outcome be collected from the included randomised controlled trials on adults to ensure that the reduction in fat was not associated with harmful effects on other major cardiovascular risk factors, and that data on changes in other dietary components be collated to help with understanding any mechanisms of action.

Sensitivity analyses assessed the effects of running fixed effects meta-analyses and excluding the largest randomised controlled trial, trials not free of systematic differences in care (or that were unclear), trials not free of dietary differences other than fat (or that were unclear), trials without or with unclear allocation concealment (an important indicator of study validity), and trials using intention to treat analyses.

Where feasible we intended to use meta-analysis on the results of cohort studies, but given the small number of included cohorts and differences in the durations between studies, the measures of body fatness, and the assessment methods of correlation between total fat intake and outcomes, meta-analysis was not appropriate. Instead, we used vote counting to describe the relation between total fat intake and body fatness in each study. We noted a positive or negative statistically significant relation between total fat intake at baseline and change in weight or body mass index over time.

We rated the quality of evidence using GRADE (Grading of Recommendations Assessment, Development and Evaluation, which provides an explicit and comprehensive method to rate quality of evidence in health) ${ }^{15}$ in GRADEpro Version 3.2 for Windows, which was debated, agreed, and the wording refined by the NUGAG subgroup on diet and health.

\section{Results}

The search for randomised controlled trials in adults identified 22012 titles and abstracts and the search for randomised controlled trials in adults and children and cohort studies identified 10208 (fig $1 \Downarrow$ ). Supplementary tables $1 \mathrm{a}$ and $\mathrm{b}$ give the search strategies in full. Of 465 full text papers assessed, 34 randomised controlled trials (33 in adults, one in children) and 13 prospective cohort studies ( 10 in adults and three in children) were included.

\section{Randomised controlled trials in adults}

Of the 33 randomised controlled trials in adults (73 589 participants), 20 were in North America, 12 in Europe, and one in New Zealand, with none from developing or transitional countries. The duration of the trials varied from six months to more than eight years. In four trials the participants were all men, in 15 all women, and in 14 both sexes (one of which reported outcomes by sex), with varying mean ages and states of health (low, moderate, or high risk of cardiovascular disease or breast cancer). See table $1 \Downarrow$ and supplementary table 2 for the characteristics of the trials in adults.

Risk of bias was variable. Randomisation was generally adequate, but allocation concealment (which may be an important predictor of study bias) was unclear in over half the trials (fig $2 \Downarrow$, also see supplementary fig 1 ). The included trials scored poorly for blinding, but this was not surprising with a dietary intervention of this type-fat intake can only really be blinded in well conducted trials by institutions or in trials of food provision by study shops. The included randomised controlled trials generally appeared free of other types of bias 
and of selective reporting. A third of the trials were free of systematic differences in care, support, time, and attention between intervention and control arms, and three quarters were free of dietary changes or advice additional to the change in fat intake.

\section{Effects of reduced fat intake on body weight}

The 33 randomised controlled trials included 38 comparisons, of which 35 provided data on body weight or weight change. Of these, eight could not be pooled as they did not provide data on variance or the control group, but seven provided enough information to be added to forest plots to allow assessment of whether their results differed from those of the pooled randomised controlled trials ("not estimable" in fig $3 \Downarrow$ ).

The main analysis was of all included randomised controlled trials with data on body weight, comparing the effect of reduction in total fat intake with usual fat intake on body weight at the latest time point. Meta-analysis suggested that the mean effect of reduction in total fat intake was a weight loss of 1.57 $\mathrm{kg}\left(95 \%\right.$ confidence interval -1.97 to $-1.16, \mathrm{I}^{2}=75 \%, 57735$ participants) in the lower fat group compared with control group (fig 3 ). In some cases this relative reduction in weight was due to a smaller increase in body weight over time in the intervention group than in the control group; in some trials weight was reduced in the low fat group but gained in the control group; and in other randomised controlled trials there was greater weight reduction in the low fat group than in the control group. The $\mathrm{I}^{2}$ of $75 \%$ suggests that although the randomised controlled trials were consistent in suggesting lower weight in the low fat compared with control groups (see fig 3 , almost all randomised controlled trials have the best estimate of effect on weight on the left side of the vertical line), heterogeneity was evident in the amount of that weight reduction. The funnel plot showed that more than $5 \%$ of studies fell outside the $95 \%$ confidence lines, but some of this was explained by baseline total fat intake subgroups,${ }^{14}$ so that the scope for distortion of results by publication bias or outcome reporting bias was limited (see supplementary fig 2).

Seven of the eight randomised controlled trials that could not be pooled concurred in having greater weight reduction in the low fat arms than in the control arms (see fig 3 for the seven studies that were not estimable) $)^{18-203233364148}$; the exception was a study ${ }^{43}$ that reported "in both groups, body weight remained unchanged after 12 months" and was not detailed enough to be shown in the forest plot. The possible presence of reporting bias was examined by using the list of included studies from a recent review of randomised controlled trials of reduced and modified fat on cardiovascular events. ${ }^{8}$ Of 48 included randomised controlled trials in the other review, 24 were included in the current review. Of the remaining 24 randomised controlled trials, 10 did not compare reduced fat intake with usual fat intake (they were included as they modified fat), ${ }^{53-63}$ and 13 aimed to reduce weight in some or all participants so were ineligible for the current review. ${ }^{64-76}$ Only one trial was eligible for this review but was not included as no data were provided on body weight, body mass index, or waist circumference. ${ }^{77}$ The risk of reporting bias, related to the proportion of studies not included in a meta-analysis, seems minimal here. ${ }^{78}$

Reasons for the observed heterogeneity in effect size were explored using subgrouping. Figure 3 shows the relation between exposure dose and outcome, with randomised controlled trials categorised by the change in percentage fat intake between the intervention and control groups. Where total fat intake differed by more than $5 \%$ of energy between intervention and control arms reductions in weight in the lower fat arm compared with usual fat arm were statistically significant. The size of the effect of reducing total fat intake on body weight did not differ substantially by participants' sex, decade when results were first published, goal of dietary fat in the intervention group, whether the level of fat in the intervention was below or above $30 \%$ of energy, baseline body mass index, or health status at baseline (table $2 \Downarrow$ ). Subgroup analysis suggested that the effects on body weight were reduced in trials of longer duration ( $>5$ years, $\mathrm{P}=0.03$ for subgroup differences), greater in those with lower baseline fat intake $(\mathrm{P}<0.001$ for subgroup differences), and with greater reduction in fat in the intervention group compared with control group ( $\mathrm{P}=0.002$ for subgroup differences).

Metaregression (multiple regression model on all three factors at once) suggested that the degree of fat reduction was significantly associated with degree of weight loss in the intervention arm compared with control arm (coefficient -0.19 $\mathrm{kg} / 1 \%$ energy from total fat reduction, $95 \%$ confidence interval -0.33 to $-0.06, \mathrm{P}=0.006$ ), suggesting that greater reduction in fat intake was associated with greater weight loss. Fat intake in the control group (equivalent to baseline fat intake) was also significantly associated with the degree of weight loss in the intervention group (coefficient $0.16 \mathrm{~kg} / 1 \%$ energy from fat in the control group, 0.05 to $0.27, \mathrm{P}=0.008$ ), suggesting that a reduction in fat intake was more effective at reducing weight in those with a lower baseline fat intake. There was no clear association between trial duration and degree of weight loss (coefficient $0.01 \mathrm{~kg} / \mathrm{month}, 95 \%$ confidence interval -0.004 to $0.029, \mathrm{P}=0.14)$. Together these factors explained $58 \%$ of variance between studies, using the equation: weight change $(\mathrm{kg})=-5.77 \mathrm{~kg}+0.16 \mathrm{~kg} / 1 \%$ energy from total fat in control group $-0.19 \mathrm{~kg} / 1 \%$ decrease in energy from total fat in intervention group $+0.01 \mathrm{~kg} /$ months' duration.

A feasible explanation for the relative weight reduction in lower fat arms might be that the participants in the intervention (low fat) groups received more time, attention, and support than those in the control arms, so that the weight loss was due to factors other than the fat content of the diet. After removing randomised controlled trials with different levels of attention or support to the low fat arms (leaving trials that worked to attain specific fat goals in the control group and those carried out in institutions or through trial shops), a statistically significantly greater reduction in weight in the lower fat arms (of $-1.4 \mathrm{~kg}$ ) remained (table $3 \Downarrow$ ). To assess whether other concomitant dietary interventions (such as encouragement to eat more fruit and vegetables in the low fat arms of some trials) may have been responsible for the weight effect, a sensitivity analysis was carried out by removing trials with dietary advice additional to the advice on low fat. The reduced weight in the low fat groups remained (table 3 ). The analyses were also repeated using fixed effect meta-analyses, excluding the largest randomised controlled trial (Women's Health Initiative) and excluding trials with unclear or no allocation concealment. In all cases the results consistently suggested that reducing total fat intake results in a small but statistically significant reduction in weight compared with usual fat intake. As no randomised controlled trials had used intention to treat analysis the relevant sensitivity analysis was omitted.

\section{Effect of fat intake on body mass index and waist circumference}

Meta-analysis of the nine randomised controlled trials with data on body mass index found a significantly lower body mass index in the low fat arms compared with usual fat arms $(-0.51,95 \%$ confidence interval -0.76 to $-0.26, \mathrm{I}^{2}=77 \%$ ). Only one 
randomised controlled trial reported waist circumference. In the Women's Health Initiative ${ }^{50}$ waist circumference in those on low fat diets was significantly lower than those on usual fat diets at five and seven years (by $0.30 \mathrm{~cm}, 95 \%$ confidence interval -0.58 to $-0.02,15671$ women). No randomised controlled trials reported body fatness.

\section{Effect of fat intake on serum lipid levels and blood pressure}

The effects of low fat intervention on serum lipid levels and blood pressure were meta-analysed and appeared positive (statistically significantly protective) for low density lipoprotein cholesterol and total cholesterol, ratio of total cholesterol to high density lipoprotein cholesterol, and systolic and diastolic blood pressure (see supplementary table 3). The effect on high density lipoprotein cholesterol levels was negative (of borderline statistical significance), and there was no clear effect on triglyceride levels.

\section{Effect of reducing fat on intake of energy, carbohydrate, sugars, protein, and alcohol}

Indications were that during the diet periods energy intake was usually lower in the low fat group than in the control or usual fat groups, and sugar intake was not measured often but where reported intakes seemed to be higher in the low fat arms (except in MeDiet ${ }^{33}$, see supplementary table 4). Carbohydrate intakes seemed almost universally higher in the low fat arms than in the usual fat arms, and protein intakes were sometimes higher and sometimes similar. There was no consistent pattern in alcohol intake. When subgroups were used to examine the effect of degree of energy reduction in the reduced fat group compared with the control group on weight loss, there was some indication that a greater degree of energy reduction in the reduced fat group was associated with greater weight reduction (see table 2 , test for subgroup differences $\mathrm{P}=0.04$, forest plot displayed in supplementary fig 4 ).

\section{Cohort studies in adults}

Ten cohort studies were in adult populations, including 107624 participants providing over 665756 person years of observation. Seven studies were based in the United States, two in Denmark, and one in Sweden. Participants were from various ethnic groups, of both sexes, and aged 18 to 80 years. Results were stratified in different studies by ethnicity (black, Caucasian, hispanic), sex, age, and level of activity (see supplementary table 5 for the characteristics of the included cohort studies and supplementary table 6 for study validity). According to our prespecified definition one study was at moderate risk of bias and the others were at high risk.

\section{Relation between baseline total fat intake and change in body fatness}

Of 16 assessments on the effects of total fat intake on subsequent weight change in seven cohorts, 11 showed no statistically significant effect and five (31\%) showed a statistically significant positive effect. Eight assessments included at least 1000 participants. Of these, three (38\%) suggested a statistically significant positive relation. Ten assessed the relation over periods of five years or more; of these, two (20\%) were significantly positive. Of the six assessments over 12-59 months, three were significantly positive $(50 \%)$.

Of four assessments of change in waist circumference in two cohorts, three suggested no significant effect and one suggested a negative effect (greater fat intake was associated with a smaller change in waist circumference). One study assessed the association of total fat intake with absolute body weight 10 years later and found a positive association in black men and women but no association in white men and women. The final study assessed the relation between total fat intake and absolute body mass index, not adjusting for energy, and found no relation. The cohort study with least risk of bias found no association between total fat intake and change in body weight over five years in either men or women.

\section{Quality of the evidence}

GRADE assessment of the evidence in adults relied on the data in the randomised controlled trials and suggested high quality evidence of the relation between total fat intake and body weight (see supplementary table 9).

\section{Randomised controlled trial and cohort studies in children and young people}

Four studies in children and young people were included: one randomised controlled trial and three prospective cohort studies. All included cohorts were from North America and the randomised controlled trial from Greece. The duration of the randomised controlled trial was 12 months and the cohort studies had one or two years' follow-up.

In the VYRONAS randomised controlled trial, 191 students aged 12-13 years were randomised at baseline to intervention or usual diet. ${ }^{79}$ The intervention group $(\mathrm{n}=98)$ took part in a 12 week school based health and nutrition interventional programme with one year's follow-up. After 12 months, total fat intake (as a percentage of energy) was significantly reduced compared with baseline in the intervention group (31.3 (SD 4.4) $v 35.4$ (SD 4.7), $\mathrm{P}<0.001$ ), but not in the control group (36.2 $(\mathrm{SD} 5.2) v 36.9$ (SD 4.8), $\mathrm{P}=0.343)$. Mean body mass index also decreased significantly (adjusting for age and sex) compared with baseline in the intervention group (23.3 (SD 2.8) v 24.0 (SD 3.1), $\mathrm{P}<0.001$ ), but remained practically unchanged in the control group (24.8 (SD 3.8) v 24.3 (SD 3.3), $\mathrm{P}=0.355$ ). The difference in weight between intervention and control arms was not reported, but our own analysis (in RevMan) of the outcome data suggests that the effect of a low fat diet compared with usual fat diet on body mass index in children was -1.50 (95\% confidence interval -2.45 to -0.55$)$; however, this was assessed on adjusted data and therefore without analysis of the original dataset this should be considered with caution.

Supplementary fig 3 summarises the validity of this randomised controlled trial. Although sequence generation and concealment of allocation seemed to be adequate and the trial dealt with incomplete outcome data it was not blinded, had systematic differences in care between intervention and control groups, and encouraged differences in diet between the two arms other than differences in dietary fat.

Supplementary table 7 summarises the risk of bias of the included cohort studies. One study was at moderate risk of bias ${ }^{80}$ and the other two at high risk. All three were funded by non-commercial bodies and all had internal control groups. One failed to adjust for three important potential confounders ${ }^{81}$ (the others failed to adjust for one or two), and in one study more than $20 \%$ of the participants were lost during follow-up. ${ }^{82}$ Two studies assessed dietary intake using 24 hour dietary recall and the other used a food frequency questionnaire. None of the studies reported baseline similarities of children by total fat intake.

Supplementary table 8 shows the characteristics of the child and young people's cohorts. The relation assessed in two studies 
was between baseline percentage of energy from fat and change in body mass index and in the other was between baseline percentage of energy from fat and weight change. For the two studies the relation was positive and statistically significant and for the third was positive and marginally significant $(\mathrm{P}=0.05)$. One of the studies ${ }^{82}$ also assessed the relations between change in percentage energy from fat from baseline to one year, one year to two years, and baseline to two years and change in body mass index over two years. One of these three relations was statistically significantly positive (the others were not statistically significant).

As the evidence in children and young people was limited, the GRADE assessment relied indirectly on findings from adults, supported by those from the studies in children. There was evidence of moderate quality for the relation between total fat intake and body weight in children and young people.

\section{Discussion}

Meta-analysis of 33 randomised controlled trials in adults suggested that diets lower in total fat on average reduced body weight by $1.6 \mathrm{~kg}$, body mass index by -0.51 , and waist circumference by $0.3 \mathrm{~cm}$. These effects were from randomised controlled trials in which weight loss was not an intended outcome, suggesting that they occur in people eating normal diets and the direction of effect on weight was consistent regardless of subgroups or sensitivity analyses. Reductions in total fat intake were associated with small but statistically significant reductions in total cholesterol, low density lipoprotein, and ratio of total to high density lipoprotein cholesterol, and in systolic and diastolic blood pressures, suggesting a lack of harm on other major cardiovascular risk factors.

Metaregression suggested that greater reduction in total fat intake and lower baseline total fat intake were associated with greater relative weight loss in studies with a total fat intake at baseline of between $28 \%$ and $43 \%$ of energy, but that any reduction in total fat will be reflected in some weight reduction relative to control. Longer study duration was not associated with a reduction in the degree of weight loss in studies of 0.5 to over eight years. Data on weight were taken from the latest reported time in each trial, which was at seven year follow-up for the single largest study, the Women's Health Initiative, which included over half of the participants in the systematic review.

Although further metabolic studies may reveal a mechanism of action, most studies that reported energy intake suggested lower energy intake in the low fat group than in the control or usual fat groups, and subgroups suggested that a greater degree of energy reduction in the low fat group (compared with control) was related to greater weight loss. This suggests that weight reduction may be due to reduced energy intake in those on low fat diets, rather than a specific effect of the macronutrient composition of the diet.

Cohort data in adults suggested either no relation between percentage of energy from total fat at baseline and weight change over one or more years, or a positive relation (in a third of comparisons). Given the strength of evidence from randomised controlled trials of a consistent effect of reducing total fat intake on weight, the general lack of association found in cohort studies is surprising. However, this may be due to the relative insensitivity of the instruments used to measure total fat intake (most studies used food frequency questionnaires, two used some form of dietary recall, although one of these was a single 24 hour recall, and one used a seven day weighed intake), the small size of the relation being sought, and the confounding effect of dieting behaviour that is common in the populations studied.

The small amount of data from the randomised controlled trials (one from Greece, 191 participants) and cohort studies (three cohorts from the United States, 1337 participants) in children and young people was confirmatory of a relation between total fat intake and subsequent weight change.

\section{Strengths and weaknesses of the review}

Strength of evidence is discussed according to the GRADE headings of risk of bias, inconsistency, indirectness, imprecision, and other factors (including dose-response). ${ }^{15}$

Although most of the randomised controlled trials in adults were unblinded and randomisation was rarely well enough described to assess allocation concealment, results from these trials were remarkably consistent. Sensitivity analyses removing randomised controlled trials without clear allocation concealment did not lose the statistically significant weight loss in the low fat arm, and neither did running fixed (rather than random) effects meta-analysis or removing randomised controlled trials with attention bias favouring those in the low fat arm, or those with other interventions alongside the reduction in fat intake. The consistent weight loss was despite the fact that none of the randomised controlled trials included intended to alter weight in either arm, and reporting bias seemed unlikely. Given the consistency and strength of the data from the randomised controlled trials in adults, the assessment of effect size and risk of bias for GRADE assessment are based on data from randomised controlled trials alone, and the risk of bias for effects in adults was low. In children the risk of bias was based on only one randomised controlled trial (191 young people aged 12-13 years) and three cohort studies (1337 people aged 3-19 years), all with flaws, so that the risk of bias was moderate.

The effects in the randomised controlled trials in adults were remarkably consistent - in almost every trial, participants with lower total fat intakes were lower in weight (on average) at the study end than participants eating a higher percentage of total fat (or gained less weight or lost more weight). The only inconsistency (where heterogeneity arose) was in the size of this effect. The heterogeneity was partly explained in subgroups and metaregression by the degree of reduction of fat intake and by the level of fat intake in the control group, together explaining $58 \%$ of the variance between studies. The reduction in weight in those on lower fat diets was seen in very different populations and from six months to several years. It was still present when we excluded trials that gave additional support, time, or encouragement to the low fat arms and included trials that delivered additional dietary interventions (on top of the change in dietary fats). Inconsistency was not considered a problem.

In children and young people the single randomised controlled trial and two of three cohort studies suggested that higher total fat intake was associated with more weight gain or higher body mass index over 1-2 years. However, the number of included studies were insufficient to assess the possibility of small study bias or to formally assess heterogeneity.

All the randomised controlled trials (in adults and young people) directly compared (and randomised participants to) lower versus higher fat intake and measured absolute or changes in body fatness outcomes. There was only indirectness in extrapolating effects to developing or transitional countries.

Imprecision in the data from adults was unlikely, as over 14 000 participants were included in trials of at least six months' duration and effect sizes were highly statistically significant. 
Although there was no imprecision for adults, imprecision was high in data from the children (although not quantifiable), and pooling was not possible.

In adults there was evidence of a dose-response gradient between total fat intake and change in weight and little evidence of publication bias. In children the number of studies were insufficient to assess either. Metabolic studies would be required to determine mechanisms of action.

\section{Comparison with other studies}

The question of whether dietary fat intake affects body weight has been investigated in several non-systematic reviews ${ }^{83} 84$ as well as some systematic reviews. One systematic review (37 trials, 9276 participants to 1997) that assessed a different set of randomised controlled trials, including those of only three weeks or more duration and some that aimed to reduce weight, found that for each decrease of $1 \%$ of energy from total fat there was a $0.28 \mathrm{~kg}$ reduction in body weight. ${ }^{5}$ Another systematic review assessed randomised controlled trials that compared ad libitum low fat diets with usual or moderate fat intake for at least two months to $1998 .{ }^{10}$ The review included 16 trials (1728 participants) for up to one year, some of which aimed at weight loss, and found that each reduction of $1 \%$ energy as total fat resulted in a $0.37 \mathrm{~kg}$ reduction in body weight. Trials that assessed short term effects or aimed to reduce weight in the low fat arms may well have overstated any effect size. Our review only included unconfounded randomised controlled trials of at least six months' duration ( 33 trials and 73589 participants) and excluded trials that aimed to reduce body weight. We found slightly more modest but clear effects on body weight, a reduction of $0.19 \mathrm{~kg}$ for each $1 \%$ energy from total fat intake. We found no systematic reviews that assessed effects in children or young people.

\section{Meaning of the findings}

Lowering total fat intake in adults compared with not lowering fat intake was associated with reductions in body weight, body mass index, and waist circumference. These effects were found in studies of more than eight years' duration, with baseline total fat intakes of $28 \%$ to $43 \%$ of energy, and in healthy adults and those with risk factors or current illness. However, these relations have not been tested in low or middle income countries. Although the evidence was slightly less strong in children, diets higher in total fat seem to be associated with higher body weight, body mass index, and waist circumference in both adults and children than diets lower in fat.

The effect on health of an individual reducing his or her body weight by $1.6 \mathrm{~kg}$ is likely to be small, but the effects of a whole population doing so would be noticeable. A systematic review of 57 cohort studies found that over a body mass index of 25 $\mathrm{kg} / \mathrm{m}^{2}$ ( $>60 \%$ of UK adults have a body mass index $>25$ ) each additional $5 \mathrm{~kg} / \mathrm{m}^{2}$ was associated with $30 \%$ greater total mortality (with contributions from deaths related to vascular, renal, hepatic, and respiratory disease, cancer, and diabetes).$^{85}$ In a man of average height $(1.75 \mathrm{~m})$ and weighing $80 \mathrm{~kg}$ a loss of $1.6 \mathrm{~kg}$ will reduce body mass index from 26.12 to 25.60 , a reduction of 0.52 , which would be associated with a reduction in total mortality of $3 \%$.

\section{Implications for public health policy and research}

Although it may be difficult for populations to reduce total fat intake, attempts should be made to do so, to help control weight, where mean total fat intake is $30 \%$ or more of energy. For populations where the mean total fat intake is below $30 \%$ of energy then interventions to restrict rises in total fat intake to over $30 \%$ of energy may help to avoid obesity. High quality trials are needed to examine the effect on body weight of reducing fat intake in developing or transitional countries with total fat intakes greater than $30 \%$ of energy, and of preventing total fat intake rising above $30 \%$ of energy in countries with total fat intakes of $25-30 \%$ of energy. High quality trials are also needed in children.

We thank the members of the WHO NUGAG subgroup on diet and health for their work in setting up the question and the protocol for this review (agreed in outline at its first meeting in February 2010, but not published), offering further studies for examination and assessment of inclusion, and in ensuring robust analysis. WHO agreed with the publication of this systematic review in a scientific journal as it serves as the background evidence review for updating WHO guidelines on total fat intake and should therefore be available widely.

Contributors: The WHO NUGAG subgroup on diet and health discussed and developed the question for this review and included $\mathrm{LH}$ and CMS. The protocol was drafted by $\mathrm{LH}$ and approved by the NUGAG subgroup on diet and health. LH, WD, and HJM carried out the searches. LH, AA, WD, HJM, and CSE assessed the eligibility of the studies for inclusion, extracted data, and assessed trial validity. LH carried out the first GRADE assessment, which was refined by the NUGAG subgroup on diet and health. WD wrote the first draft of the report for the review by the NUGAG subgroup on diet and health. LH wrote the first draft of this paper. All authors contributed to the analysis, as did the NUGAG subgroup on diet and health in response to the first draft of the review. All authors agreed on the final draft of this review. $\mathrm{LH}$ is the guarantor. Funding: WHO provided funding to Durham University towards the cost of carrying out this systematic review. No funding was received for the searching, analysis, or writing up of the data from randomised controlled trials in adults, but it was supported by the Norwich Medical School, University of East Anglia. The funders did not have any vested interests in the findings of this research.

Competing interests: All authors have completed the ICMJE uniform disclosure form at www.icmje.org/coi_disclosure.pdf (available on request from the corresponding author) and declare: CMS, WD, and HJM had financial support from the WHO for the submitted work; LH and CMS received funding from WHO to attend meetings of the NUGAG subgroup on diet and health; $\mathrm{LH}$ received research funding to carry out a systematic reviews for Barry Callebaut (to assess the effects of chocolate on markers of antioxidant status, funding ceased in August 2010); no further financial relationships existed with any organisations that might have an interest in the submitted work in the previous three years; no other relationships or activities that could appear to have influenced the submitted work.

Ethical approval: Not required.

Data sharing: No additional data available.

World Cancer Research Fund/American Institute for Cancer Research. Preventability of cancer by food, nutrition, and physical activity: Appendix A. Policy and Action for Cancer cancer by food, nutrition, and physical activity: Appendix A. Policy and Action for Cancer
Prevention. Food, Nutrition, and Physical Activity: a Global Perspective. AICR, 2009. Manson JE, Colditz GA, Stampfer MJ, Willett WC, Rosner B, Monson RR, et al. A prospective study of obesity and risk of coronary heart disease in women. N Engl J Med 1990;322:882-9.

3 Song Y-M, Sung J, Davey Smith G, Ebrahim S. Body mass index and ischemic and hemorrhagic stroke: a prospective study in Korean men. Stroke 2004;35:831-6.

4 Kelly S, Hillier F, Whittaker V, Ells LJ, Edmunds LD, Smith S, et al. The associations between food, nutrition, physical activity and the risk of weight gain, overweight and obesity and underlying mechanisms. World Cancer Research Fund/American Institute for Cancer Research, 2006 www.dietandcancerreport.org/cancer_resource_center/downloads/SLR/ Obesity_SLR.pdf.

5 Yu-Poth S, Zhao G, Etherton T, Naglak M, Jonnalagadda S, Kris-Etherton PM. Effects of the National Cholesterol Education Program's Step I And Step II dietary intervention programs on cardiovascular disease risk factors: a meta-analysis. Am J Clin Nutr 1999;69:632-46.

6 Higgins JPT, Green S. Cochrane handbook for systematic reviews of interventions version 5.0.2 [updated September 2009]. Available from www.cochrane-handbook.org. 


\section{What is already known on this topic}

The ideal proportion of total fat in the human diet is unclear but it would help to understand the relation between total fat intake and body weight

Two systematic reviews may have overstated relations in adults by including studies of short duration and those that encouraged weight reduction

No systematic reviews have assessed the relation in children or young people

\section{What this study adds}

This systematic review found that lowering the proportion of energy intake from total fat was associated with lower body weight (by 1.6 $\mathrm{kg}$ ), body mass index, and waist circumference in adults

Each $1 \%$ decrease in energy from total fat resulted in a $0.19 \mathrm{~kg}$ reduction in body weight, compared with not altering total fat intake, in populations with $28-43 \%$ of energy from total fat, and in studies of six months to over eight years

Evidence in children and young people is more limited, but supports the relation in adults

7 World Health Organization. WHO Handbook for guideline development. WHO, 2010. www.who.int/hiv/topics/mtct/grc_handbook_mar2010_1.pdfed. Geneva, Switzerland: World Health Organisation; 2010

8 Hooper L, Summerbell CD, Thompson R, Sills D, Roberts FG, Moore HJ, et al. Reduced or modified dietary fat for preventing cardiovascular disease. Cochrane Database Syst Rev 2012;(5):CD002137.

9 Summerbell CD, Douthwaite W, Whittaker V, Ells LJ, Hillier F, Smith S, et al. The association between diet and physical activity and subsequent excess weight gain and obesity assessed at 5 years of age or older: a systematic review of the epidemiological evidence. Int $J$ Obes 2009;33(Suppl 3):S1-92.

10 Astrup A, Ryan L, Grunwald GK, Storgaard M, Saris W, Melanson E, et al. The role of dietary fat in body fatness: evidence from a preliminary meta-analysis of ad libitum low-fat dietary intervention studies. Br J Nutr 2000;83(Supp 1):S25-32.

11 Wells GA, Shea B, O'Connell D, Peterson J, Welch V, Losos M, et al. The Newcastle-Ottawa Scale (NOS) for assessing the quality of nonrandomised studies in meta-analyses. 2011. www.ohri.ca/programs/clinical_epidemiology/oxford.htm.

12 Higgins JPT, Thompson SG, Deeks JJ, Altman DG. Measuring inconsistency in meta-analyses. BMJ 2003;327:557-60.

13 Egger M, Davey Smith G, Schneider M, Minder C. Bias in meta-analysis detected by a simple graphical test. BMJ 1997;315:629-34.

14 Sterne JAC, Sutton AJ, loannidis JP, Terrin N, Jones DR, Carpenter J, et al. Recommendations for examining and interpreting funnel plot asymmetry in meta-analyses of randomised controlled trials. BMJ 2011;343:d4002.

15 Guyatt GH, Oxman AD, Vist G, Kunz R, Falck-Ytter Y, Alonso-Coello P, et al. Rating quality of evidence and strength of recommendations GRADE: an emerging consensus on rating quality of evidence and strength of recommendations. BMJ 2008;336:924-6.

16 Ley SJ, Metcalf PA, Scragg RKR, Swinburn BA. Long-term effects of a reduced fat diet intervention on cardiovascular disease risk factors in individuals with glucose intolerance. Diabetes Res Clin Pract 2004;63:103-12.

17 Boyd NF, Martin LJ, Beaton M, Cousins M, Kriukov V. Long-term effects of participation in a randomized trial of a low-fat, high-carbohydrate diet. Cancer Epidemiol Biomarkers Prev 1996;5:217-22.

18 Retzlaff BM, Walden CE, McNeney WB, Buck BL, McCann BS, Knopp RH. Nutritional intake of women and men on the NCEP Step I and Step II diets. J Am Coll Nutr 1997;16:52-61.

19 Walden CE, Retzlaff BM, Buck BL, McCann BS, Knopp RH. Lipoprotein lipid response to the National Cholesterol Education Program Step II diet by hypercholesterolemic and combined hyperlipidemic women and men. Arterioscler Thromb Vasc Biol 1997:17:375-82.

20 Walden CE, Retzlaff BM, Buck BL, Wallick S, McCann BS, Knopp RH. Differential effect of National Cholesterol Education Program (NCEP) Step II Diet on HDL cholesterol, its subfractions, and apoprotein A-1 levels in hypercholesterolemic women and men after 1 year: the beFIT study. Arterioscler Thromb Vasc Biol 2000;20:1580-7.

21 Bloemberg BPM, Kromhout D, Goddijn HE, Jansen A, Obermann de Boer GL. The impact for the guidelines for a healthy diet of the Netherlands Nutrition Council on total and high density lipoprotein cholesterol in hypercholesterolemic free living men. Am J Epidemiol 1991;134:39-48.

22 Hebert JR, Ebbeling CB, Olendzki BC, Hurley TG, Ma Y, Saal N, et al. Change in women's diet and body mass following intensive intervention for early-stage breast cancer. J Am Diet Assoc 2001;101:421-31.

23 Boyd NF, Lockwood GA, Greenberg CV, Martin LJ, Tritchler DL, Boyd NF, et al. Effects of a low-fat high-carbohydrate diet on plasma sex hormones in premenopausal women: results from a randomized controlled trial. Canadian Diet and Breast Cancer Prevention Study Group. Br J Cancer 1997;76:127-35.

24 Poppitt SD, Keogh GF, Prentice AM, Williams DEM, Sonnemans HMW, Valk EEJ, et al. Long-term effects of ad libitum low-fat, high-carbohydrate diets on body weight and serum lipids in overweight subjects with metabolic syndrome. Am J Clin Nutr 2002;75:11-20.

25 Saris WHM, Astrup A, Prentice AM, Zunft HJF, Formiguera X, Verboeket-van de Venne WPHG, et al. Randomized controlled trial of changes in dietary carbohydrate/fat ratio and simple vs complex carbohydrates on body weight and blood lipids: the CARMEN study. Int J Obes 2000;24:1310-8.

26 De Bont AJ, Baker IA, St, Sweetnam PM, Wragg KG, Stephens SM, et al. A randomised controlled trial of the effect of low fat diet advice on dietary response in insulin independent diabetic women. Diabetologia 1981;21:529-33.

27 Stefanick ML, Mackey S, Sheehan RD, Ellsworth N, Haskell WL, Wood PD. Effects of diet and exercise in men and postmenopausal women with low levels of HDL cholestero and high levels of LDL cholesterol. N Engl J Med 1998;339:12-20.

28 Seppelt B, Weststrate JA, Reinert A, Johnson D, Luder W, Zunft HJ. Long-term effects of nutrition with fat-reduced foods on energy consumption and body weight. $Z$ Ernahrungswiss 1996;35:369-77.

29 Anderson JW, Garrity TF, Smith BM, Whitis SE. Follow-up on a clinical trial comparing the effects of two lipid lowering diets. Arteriosclerosis 1990;10:882a.

30 Anderson JW, Garrity TF, Wood CL, Whitis SE, Smith BM, Oeltgen PR. Prospective, randomized, controlled comparison of the effects of low-fat and low-fat plus high-fiber diets on serum lipid concentrations. Am J Clin Nutr 1992;56:887-94.
31 Sarkkinen E. Long-term feasibility and effects of three different fat-modified diets in free-living hypercholesterolemic subjects. [Thesis]. University of Kuopio, 1995.

32 Boyd NF, McGuire V, Shannon P, Cousins M, Kriukov V, Mahoney L, et al. Effect of a low-fat high-carbohydrate diet on symptoms of cyclical mastopathy. Lancet 1988;2:128-32.

33 Castagnetta L, Granata OM, Cusimano R, Ravazzolo B, Liquori M, Polito L, et al. The Mediet Project. Ann N Y Acad Sci 2002;963:282-9.

34 Moy TF, Yanek LR, Raqueno JV, Bezirdjian PJ, Blumenthal RS, Wilder LB, et al. Dietary counseling for high blood cholesterol in families at risk of coronary disease. Prevent Cardiol 2001;4:158-64

35 Van het Hof KH, Weststrate JA, van den Berg H, Velthuis-te Wierik EJ, de Graaf C Zimmermanns $\mathrm{NJ}$, et al. A long-term study on the effect of spontaneous consumption of reduced fat products as part of a normal diet on indicators of health. Int $J$ Food Sci Nutr 1997; 48:19-29.

36 NDHS. The national diet-heart study final report. Circulation 1968;37(II):1-428.

37 Djuric Z, Poore KM, Depper JB, Uhley VE, Lababidi S, Covington C, et al. Methods to increase fruit and vegetable intake with and without a decrease in fat intake: compliance and effects on body weight in the Nutrition and Breast Health Study. Nutr Cancer 2002;43:141-51.

38 Pilkington TRE, Stafford JL, Hankin VS, Simmonds FM, Koerselman HB. Practical diets for lowering serum lipids. BMJ 1960;1:23-5.

39 Lanza E, Schatzkin A, Ballard BR, Clifford DC, Paskett E, Hayes D, et al. The polyp prevention trial II: dietary intervention program and participant baseline dietary characteristics. Cancer Epidemiol Biomarkers Prev 1996;5:385-92.

40 Schatzkin A, Lanza E, Freedman LS, Tangrea J, Cooper MR, Marshall JR, et al. The polyp prevention trial I: rationale, design, recruitment, and baseline participant characteristics. Cancer Epidemiol Biomarkers Prev 1996;5:375-83.

41 Rivellese AA, Auletta P, Marotta G, Saldalamacchia G, Giacoo A, Mastrilli V, et al. Long term metabolic effects of two dietary methods of treating hyperlipidaemia. BMJ 1994;308:227-31

42 Simon MS, Heilbrun LK, Boomer A, Kresge C, Depper J, Kim PN, et al. A randomised trial of a low-fat dietary intervention in women at high risk for breast cancer. Nutr Cancer 1997;27:136-42.

43 Sondergaard E, Moller JE, Egstrup K. Effect of dietary intervention and lipid-lowering treatment on brachial vasoreactivity in patients with ischemic heart disease and hypercholesterolemia. Am Heart J 2003;145:E19.

44 Strychar I, Cohn JS, Renier G, Rivard M, ris-Jilwan N, Beauregard H, et al. Effects of a diet higher in carbohydrate/lower in fat versus lower in carbohydrate/higher in monounsaturated fat on postmeal triglyceride concentrations and other cardiovascular risk factors in type 1 diabetes. Diabetes Care 2009;32:1597-9.

45 Holm LE, Nordevang E, Ikkala E, Hallstrom L, Callmer E. Dietary intervention as adjuvant therapy in breast cancer patients-a feasibility study. Breast Cancer Res Treat 1990;16:103-9.

46 Nordevang E, Callmer E, Marmur A, Holm LE. Dietary intervention in breast cancer patients: effects on food choice. Eur J Clin Nutr 1992;46:387-96.

47 Nordevang E, Ikkala E, Callmer E, Hallstrom L, Holm LE. Dietary intervention in breast cancer patients: effects on dietary habits and nutrient intake. Eur J Clin Nutr 1990;44:681-7.

48 Black HS, Herd JA, Goldberg LH, Wolf-JE J, Thornby JI, Rosen T, et al. Effect of a low-fat diet on the incidence of actinic keratosis. N Engl $J$ Med 1994;330:1272-5.

49 Pierce JP, Natarajan L, Caan BJ, Parker BA, Greenberg ER, Flatt SW, et al. Influence of a diet very high in vegetables, fruit, and fiber and low in fat on prognosis following treatment for breast cancer: the Women's Healthy Eating and Living (WHEL) randomized trial. JAMA 2007;298:289-98

50 Howard BV, Manson JE, Stefanick ML, Beresford SA, Frank G, Jones B, et al. Low-fat dietary pattern and weight change over 7 years: the Women's Health Initiative Dietary Modification Trial. JAMA 2006;295:39-49.

51 Hall WD, Feng Z, George VA, Lewis CE, Oberman A, Huber M, et al. Low-fat diet: effec on anthropometrics, blood pressure, glucose and insulin in older women. Ethn Dis 2003;13:337-43.

52 Chlebowski RT, Blackburn GL, Buzzard IM, Rose DP, Martino S, Khandekar JD, et al. Adherence to a dietary fat intake reduction program in postmenopausal women receiving therapy for early breast cancer. The Women's Intervention Nutrition Study. J Clin Oncol 1993:11:2072-80.

53 Curzio JL, Kennedy SS, Elliott HL, Farish E, Barnes JF, Howie CA, et al. Hypercholesterolaemia in treated hypertensives: a controlled trial of intensive dietary advice. J Hypertens Suppl 1989;7:S254-5.

54 Dullaart RP, Beusekamp BJ, Meijer S, Hoogenberg K, van Doormaal JJ, Sluiter WJ. Long-term effects of linoleic-acid-enriched diet on albuminuria and lipid levels in type 1 (insulin-dependent) diabetic patients with elevated urinary albumin excretion. Diabetologia 1992;35:165-72.

55 Frenkiel PG, Lee DW, Cohen H, Gilmore CJ, Resser K, Bonorris GG, et al. The effect of diet on bile acid kinetics and biliary lipid secretion in gallstone patients treated with ursodeoxycholic acid. Am J Clin Nutr 1986;43:239-50.

56 Houtsmuller AJ, Zahn KJ, Henkes HE. Unsaturated fats and progression of diabetic retinopathy. Doc Ophthalmol 1979;48:363-71. 
57 Frantz ID J, Dawson EA, Ashman PL, Gatewood LC, Bartsch GE, Kuba K, et al. Test of effect of lipid lowering by diet on cardiovascular risk. The Minnesota Coronary Survey. Arteriosclerosis 1989;9:129-35.

58 Ederer F, Leren P, Turpeinen O, Frantz ID Jr. Cancer among men on cholesterol lowering diets: experience of five clinical trials. Lancet 1971;2:203-6.

59 MRC. Controlled trial of soya-bean oil in myocardial infarction. Lancet 1968;2:693-9.

60 Leren $\mathrm{P}$. The effect of plasma cholesterol lowering diet in male survivors of myocardial infarction. A controlled clinical trial. Acta Med Scand Suppl 1966:466:1-92.

61 Rose GA, Thomson WB, Williams RT. Corn oil in treatment of ischaemic heart disease. BMJ 1965;1:1531-3.

62 Woodhill JM, Palmer AJ, Leelarthaepin B, McGilchrist C, Blacket RB. Low fat, low cholesterol diet in secondary prevention of coronary heart disease. Adv Exp Med Biol 1978;109:317-30

63 Dayton S, Pearce ML, Hashimoto S, Dixon WJ, Tomayasu U. A controlled clinical trial of a diet high in unsaturated fat in preventing complications of atherosclerosis. Circulation 1969;15(1, Suppl 2):II-63.

64 Azadbakht L, Mirmiran P, Esmaillzadeh A, Azizi F. Better dietary adherence and weight maintenance achieved by a long-term moderate fat diet. Br J Nutr 2007;97:399-404.

65 Ball KP, Hanington E, McAllen PM, Pilkington TRE, Richards JM, Sharland DE, et al. Low-fat diet in myocardial infarction: a controlled trial. Lancet 1965;2:501-4.

66 Burr ML, Fehily AM, Gilbert JF, Rogers S, Holliday RM, Sweetnam PM, et al. Effects of changes in fat, fish, and fibre intakes on death and myocardial reinfarction: diet and reinfarction trial (DART). Lancet 1989;2:757-61.

67 Hjerkinn EM, Seljeflot I, Ellingsen I, Berstad P, Hjermann I, Sandvik L, et al. Influence of long-term intervention with dietary counselling, long-chain n-3 fatty acid supplements, or both on circulating markers of endothelial activation in men with long-standing hyperlipidemia. Am J Clin Nutr 2005;81:583-9.

68 Due A, Larsen TM, Mu H, Hermansen K, Stender S, Astrup A. Comparison of 3 ad libitum diets for weight-loss maintenance, risk of cardiovascular disease, and diabetes: a 6-mo randomized, controlled trial. Am J Clin Nutr 2008;88:1232-41.

69 Lean MEJ, Han TS, Prvan T, Richmond PR, Avenell A. Weight loss with high and low carbohydrate $1200 \mathrm{kcal}$ diets in free living women. Eur J Clin Nutr 1997:51:243-8.

70 McAuley KA, Hopkins CM, Smith KJ, McLay RT, Williams SM, Taylor RW, et al. Comparison of a high-fat and high-protein diets with a high-carbohydrate diet in insulin-resistant obese women. Diabetologia 2005;48:8-16.

71 Bray GA, Lovejoy JC, Most-Windhauser M, Smith SR, Volaufova J, Denkins Y, et al. A 9-mo randomized clinical trial comparing fat-substituted and fat-reduced diets in healthy obese men: the Ole Study. Am J Clin Nutr 2002;76:928-34.

72 Hockaday TD, Hockaday JM, Mann JI, Turner RC. Prospective comparison of modified fat-high-carbohydrate with standard low-carbohydrate dietary advice in the treatment of diabetes: one year follow-up study. Br J Nutr 1978;39:357-62

73 Appel LJ, Champagne CM, Harsha DW, Cooper LS, Obarzanek E, Elmer PJ, et al. Effects of comprehensive lifestyle modification on blood pressure control: main results of the PREMIER clinical trial. JAMA 2003;289:2083-93.
74 Sacks FM, Bray GA, Carey VJ, Smith SR, Ryan DH, Anton SD, et al. Comparison of weight-loss diets with different compositions of fat, protein, and carbohydrates. N Engl $J$ Med 2009;360:859-73.

75 Watts GF, Lewis B, Brunt JN, Lewis ES, Coltart DJ, Smith LD, et al. Effects on coronary artery disease of lipid-lowering diet, or diet plus cholestyramine, in the St Thomas' Atherosclerosis Regression Study (STARS). Lancet 1992;339:563-9.

76 Tuttle KR, Shuler LA, Packard DP, Milton JE, Daratha KB, Bibus DM, et al. Comparison of low-fat versus Mediterranean-style dietary intervention after first myocardial infarction (from The Heart Institute of Spokane Diet Intervention and Evaluation Trial). Am J Cardio 2008;101:1523-30

77 McKeown-Eyssen GE, Bright-See E, Bruce WR, Jazmaji V, Toronto Polyp Prevention Group. A randomized trial of a low fat high fibre diet in the recurrence of colorectal polyps. J Clin Epidemiol 1994;47:525-36.

78 Furukawa TA, Watanabe N, Montori VM, Guyatt GH. Association between unreported outcomes and effect size estimates in Cochrane meta-analyses. JAMA 2007:297:468-70.

79 Minas C, Mariolis A, Manios Y, Naska A, Arapaki A, Mariolis-Sapsakos T, et al. Evaluation of a nutrition intervention in adolescents of an urban area in Greece: short- and long-term effects of the VYRONAS study. Public Health Nutr 2010;13:712-9.

80 Davison KK, Birch LL. Child and parent characteristics as predictors of change in girls' body mass index. Int J Obes 2001;25:1834-42.

81 Butte NF, Cai G, Cole SA, Wilson TA, Fisher JO, Zakeri IF, et al. Metabolic and behavioral predictors of weight gain in Hispanic children: the Viva la Familia Study. Am Jf Clin Nutr 2007;85:1478-85.

82 Klesges RC, Klesges LM, Eck LH, Shelton ML. A longitudinal analysis of accelerated weight gain in preschool children. Pediatrics 1995;95:126-30.

83 Willett WC. Dietary fat plays a major role in obesity: no. Obesity reviews 2002;3:59-68.

84 Bray GA, Popkin BM. Dietary fat intake does affect obesity! Am J Clin Nutr 1998;68:1157-73.

85 Prospective Studies Collaboration. Body-mass index and cause-specific mortality in 900,000 adults: collaborative analyses of 57 prospective studies. Lance 2009;373:1083e96.

\section{Accepted: 7 November 2012}

\section{Cite this as: BMJ 2012;345:e7666}

This is an open-access article distributed under the terms of the Creative Commons Attribution Non-commercial License, which permits use, distribution, and reproduction in any medium, provided the original work is properly cited, the use is non commercial and is otherwise in compliance with the license. See: http://creativecommons.org/licenses/by$\mathrm{nc} / 2.0 /$ and http://creativecommons.org/licenses/by-nc/2.0/legalcode. 


\section{Tables}

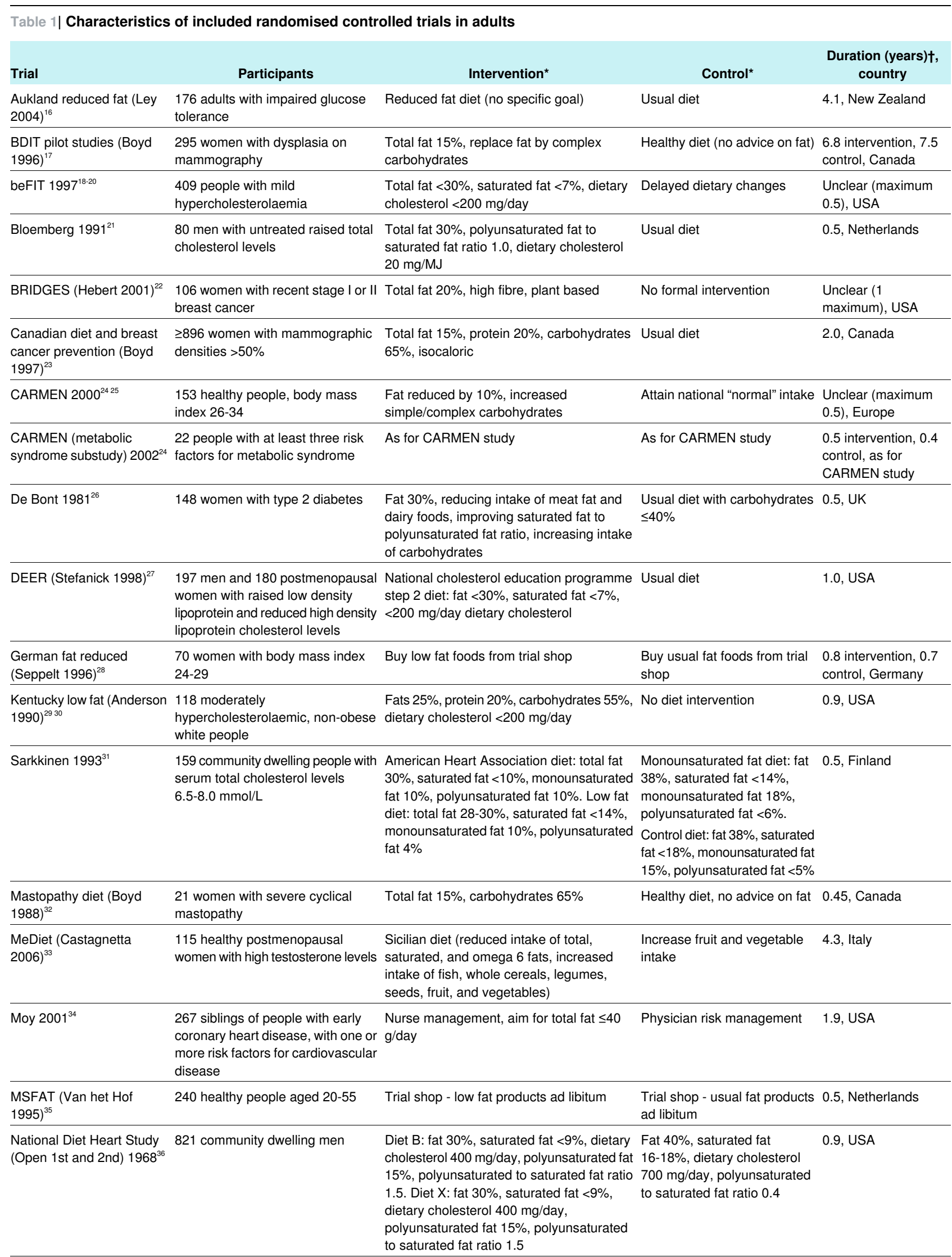


Table 1 (continued)

\begin{tabular}{|c|c|c|c|c|}
\hline Trial & Participants & Intervention* & Control* & $\begin{array}{c}\text { Duration (years) }+, \\
\text { country }\end{array}$ \\
\hline $\begin{array}{l}\text { National Diet Heart Study } \\
\text { (Open 2nd) } 1968^{36}\end{array}$ & 498 community dwelling men & $\begin{array}{l}\text { Diet } \mathrm{BC} \text { fat } 30-40 \% \text {, saturated fat reduced, } \\
\text { dietary cholesterol } 400 \mathrm{mg} / \text { day, } \\
\text { polyunsaturated to saturated fat ratio } 1.5-2.0\end{array}$ & $\begin{array}{l}\text { Fat } 40 \% \text {, saturated fat } \\
16-18 \% \text {, dietary cholesterol } \\
700 \mathrm{mg} / \text { day, polyunsaturated } \\
\text { to saturated fat ratio } 0.4\end{array}$ & 0.6 , USA \\
\hline $\begin{array}{l}\text { Nutrition and breast health } \\
\text { (Djuric 2002) }^{37}\end{array}$ & $\begin{array}{l}122 \text { premenopausal women at } \\
\text { increased risk of breast cancer }\end{array}$ & Total fat $15 \%$ & Daily food guide pyramid & $\begin{array}{l}0.8 \text { intervention, } 1.0 \\
\text { control, USA }\end{array}$ \\
\hline Pilkington $1960^{38}$ & $\begin{array}{l}35 \text { men with angina or who had a } \\
\text { myocardial infarction }\end{array}$ & $\begin{array}{l}\text { Fat } 20 \mathrm{~g} / \text { day, avoid dairy except skimmed } \\
\text { milk and one egg or } 21 \mathrm{~g} \text { cheese daily. Lean } \\
\text { meat and fish each once daily, } \\
\text { carbohydrates unlimited }\end{array}$ & $\begin{array}{l}\text { Aims for fat intake unclear, } \\
\text { only skimmed milk, } 90 \mathrm{~mL} / \text { day } \\
\text { soya oil, lean meat, } \\
\text { unsaturated margarine }\end{array}$ & 1.1, UK \\
\hline $\begin{array}{l}\text { Polyp Prevention Trial } \\
1996^{39} 40\end{array}$ & $\begin{array}{l}2079 \text { people with one or more large } \\
\text { bowel polyps }\end{array}$ & $\begin{array}{l}\text { Fat } 20 \%, 18 \mathrm{~g} \text { fibre } / 1000 \mathrm{kcal}, 5-8 \text { servings } \\
\text { daily of fruit and vegetables }\end{array}$ & General dietary guidelines & 3.1, USA \\
\hline Rivellese $1994^{41}$ & $\begin{array}{l}63 \text { adults with primary } \\
\text { hyperlipoproteinaemia }\end{array}$ & $\begin{array}{l}\text { Fat } 25 \% \text {, saturated fat } 8 \% \text {, } \\
\text { monounsaturated fat } 15 \% \text {, polyunsaturated } \\
\text { fat } 2 \% \text {, dietary cholesterol }<300 \mathrm{mg} / \text { day, } \\
\text { carbohydrates } 58 \%\end{array}$ & $\begin{array}{l}\text { Fat } 38 \% \text {, saturated fat }<10 \% \text {, } \\
\text { monounsaturated fat } 20 \% \text {, } \\
\text { polyunsaturated fat } 10 \% \text {, } \\
\text { dietary cholesterol }<300 \\
\text { mg/day, carbohydrates } 47 \%\end{array}$ & 0.4 , Italy \\
\hline $\begin{array}{l}\text { Simon low fat breast cancer } \\
1990^{42}\end{array}$ & $\begin{array}{l}194 \text { women at high risk of breast } \\
\text { cancer }\end{array}$ & Total fat $15 \%$ & Usual diet & $\begin{array}{l}1.7 \text { intervention, } 1.8 \\
\text { control, USA }\end{array}$ \\
\hline Sondergaard $2003^{43}$ & $\begin{array}{l}115 \text { people with ischaemic heart } \\
\text { disease plus total cholesterol } \geq 5 \\
\mathrm{mmol} / \mathrm{L}\end{array}$ & $\begin{array}{l}\text { Fat and saturated fat reduced, replace fats } \\
\text { with oils, } 600 \mathrm{~g} \text { fruit and vegetables daily, } \\
\text { fatty fish once or more weekly, } \\
\text { carbohydrates freely }\end{array}$ & Unclear & 1.0, Denmark \\
\hline Strychar $2009^{44}$ & $\begin{array}{l}30 \text { people with well controlled type } \\
1 \text { diabetes mellitus }\end{array}$ & $\begin{array}{l}\text { Fat } 27-30 \% \text {, saturated fat } \leq 10 \% \text {, } \\
\text { monounsaturated fat } 10 \% \text {, carbohydrates } \\
54-57 \%\end{array}$ & $\begin{array}{l}\text { Fat } 38 \% \text {, saturated fat } \leq 10 \% \text {, } \\
\text { monounsaturated fat } 20 \% \text {, } \\
\text { carbohydrates } 45 \%\end{array}$ & 0.5, Canada \\
\hline $\begin{array}{l}\text { Swedish breast cancer } \\
1990^{45-47}\end{array}$ & $\begin{array}{l}169 \text { women after breast cancer } \\
\text { surgery }\end{array}$ & $\begin{array}{l}\text { Fat } 20-25 \% \text {, replace energy with } \\
\text { carbohydrates }\end{array}$ & Usual diet & $\begin{array}{l}1.5 \text { intervention, } 1.9 \\
\text { control, Sweden }\end{array}$ \\
\hline $\begin{array}{l}\text { Veterans dermatology } \\
(\text { Black 1994) }\end{array}$ & $\begin{array}{l}115 \text { people with non-melanoma skin } \\
\text { cancer }\end{array}$ & Fat $20 \%$, protein $15 \%$, carbohydrates $65 \%$ & No dietary advice & 1.9, USA \\
\hline $\begin{array}{l}\text { Women's Healthy Eating } \\
\text { and Living (Pierce 2007) }\end{array}$ & $\begin{array}{l}3088 \text { women with breast cancer } \\
\text { treated early }\end{array}$ & $\begin{array}{l}\text { Fat } 15-20 \% \text {, increase intake of fruit and } \\
\text { vegetables plus } 16 \text { oz vegetable juice daily }\end{array}$ & Fat $30 \%$ & 11 USA \\
\hline $\begin{array}{l}\text { Women's Health Initiative } \\
(\text { Howard 2006) })^{50}\end{array}$ & 48835 postmenopausal women & $\begin{array}{l}\text { Fat } 20 \% \text {, with increased intake of fruit, } \\
\text { vegetables, and grains }\end{array}$ & Unclear, diet related education & 8.1, USA \\
\hline $\begin{array}{l}\text { Women's Health Trial: } \\
\text { Feasibility } 1990^{51}\end{array}$ & 261 women at risk of breast cancer & Fat $20 \%$ & Usual diet & 1.9, USA \\
\hline $\begin{array}{l}\text { Women's Health Trial: } \\
\text { Feasibility Study in Minority } \\
\text { Populations } 2003^{51}\end{array}$ & $\begin{array}{l}1720 \text { postmenopausal women, } \\
\text { diverse ethnic and socioeconomic } \\
\text { status }\end{array}$ & $\begin{array}{l}\text { Fat } \leq 20 \% \text {, reduced saturated fat and dietary } \\
\text { cholesterol, increased fruit, vegetables, and } \\
\text { whole grains }\end{array}$ & Usual diet & $\begin{array}{l}\text { Unclear ( } 1.5 \\
\text { maximum), USA }\end{array}$ \\
\hline $\begin{array}{l}\text { Women's Intervention } \\
\text { Nutrition Study (Chlebowski } \\
1993)^{52}\end{array}$ & $\begin{array}{l}2437 \text { women with resected breast } \\
\text { cancer }\end{array}$ & Fat $15-20 \%$ & Nutritional adequacy & 5.0, USA \\
\hline
\end{tabular}

*Percentages refer to proportion of total energy intake.

†Mean years in trial (not maximal duration). 


\section{Table 2| Subgroups of results from randomised controlled trials in adults}

\begin{tabular}{|c|c|c|}
\hline Subgroup factor, group & Effect size in $\mathbf{k g}(95 \% \mathrm{Cl})$ & No of comparisons, $I^{2}(\%)$ \\
\hline Overall analysis: all arms & $-1.57(-1.97$ to -1.16$)$ & 27,75 \\
\hline \multicolumn{3}{|l|}{ Study duration (months): } \\
\hline $6-11$ & $-1.75(-2.28$ to -1.22$)$ & 13,63 \\
\hline $12-23$ & $-2.00(-2.51$ to -1.48$)$ & 17,71 \\
\hline $24-59$ & $-1.18(-1.65$ to -0.70$)$ & 9,56 \\
\hline$\geq 60$ & $-0.68(-1.66$ to 0.29$)$ & 4,58 \\
\hline \multicolumn{3}{|c|}{ Control group fat intake (\% energy): } \\
\hline$>35$ & $-1.20(-1.62$ to -0.78$)$ & 11,64 \\
\hline$>30-35$ & $-1.06(-1.96$ to -0.17$)$ & 10,69 \\
\hline$>25-30$ & $-2.97(-3.60$ to -2.33$)$ & 5,1 \\
\hline \multicolumn{3}{|l|}{ Participant sex: } \\
\hline Men & $-2.74(-4.32$ to -1.17$)$ & 4,76 \\
\hline Women & $-1.42(-1.93$ to -0.92$)$ & 16,70 \\
\hline Mixed & $-1.27(-2.08$ to -0.47$)$ & 7,75 \\
\hline \multicolumn{3}{|l|}{ Publication decade: } \\
\hline $1960 \mathrm{~s}$ & $-4.10(-8.06$ to -0.14$)$ & 1 \\
\hline 1970 s & No trials & \\
\hline $1980 \mathrm{~s}$ & $-0.91(-1.80$ to -0.01$)$ & 3,0 \\
\hline $1990 \mathrm{~s}$ & $-1.94(-2.57$ to -1.31$)$ & 16,77 \\
\hline $2000 \mathrm{~s}$ & $-0.95(-1.57$ to -0.33$)$ & 7,72 \\
\hline \multicolumn{3}{|c|}{ Fat intake goal in intervention group (\% energy): } \\
\hline$\geq 35$ & No data & \\
\hline $30-34$ & $-0.96(-1.66$ to -0.26$)$ & 3,0 \\
\hline $25-29$ & $-2.39(-3.82$ to -0.97$)$ & 6,87 \\
\hline 20-24 & $-0.85(-1.13$ to -0.57$)$ & 6,14 \\
\hline $15-19$ & $-1.28(-2.19$ to -0.37$)$ & 7,58 \\
\hline \multicolumn{3}{|c|}{ Difference in fat intake between intervention and control (\% energy): } \\
\hline$\leq 5$ & $-0.19(-0.88$ to 0.50$)$ & 6,19 \\
\hline $5-9$ & $-2.08(-2.77$ to -1.39$)$ & 13,82 \\
\hline $10-14$ & $-1.34(-1.70$ to -0.98$)$ & 4,26 \\
\hline$\geq 15$ & $-3.89(-8.76$ to 0.99$)$ & 3,68 \\
\hline \multicolumn{3}{|c|}{ Fat intake in intervention (control $>30 \%$ energy): } \\
\hline$>30$ & $-0.83(-1.29$ to -0.38$)$ & 6,0 \\
\hline$\leq 30$ & $-1.20(-1.69$ to -0.72$)$ & 15,74 \\
\hline \multicolumn{3}{|l|}{ Baseline body mass index: } \\
\hline$<25$ & $-0.96(-1.69$ to -0.22$)$ & 8,56 \\
\hline $25-29$ & $-1.82(-2.37$ to -1.28$)$ & 16,82 \\
\hline$\geq 30$ & $-2.06(-2.96$ to -1.17$)$ & 2,0 \\
\hline \multicolumn{3}{|l|}{ Baseline health status: } \\
\hline Healthy & $-0.98(-1.56$ to -0.41$)$ & 3,87 \\
\hline Risk factors & $-2.11(-2.93$ to -1.29$)$ & 15,74 \\
\hline IIIness & $-1.20(-1.85$ to -0.56$)$ & 9,44 \\
\hline \multicolumn{3}{|c|}{ Energy intake* in reduced fat group compared with control: } \\
\hline Same or greater & $-0.51(-1.49$ to 0.49$)$ & 4,25 \\
\hline 4-418 kJ/day lower & $-1.49(-2.92$ to -0.06$)$ & 4,66 \\
\hline 419-837 kJ/day lower & $-1.14(-2.24$ to -0.04$)$ & 5,80 \\
\hline$>837 \mathrm{~kJ} /$ day lower & $-2.15(-2.78$ to -1.52$)$ & 11,77 \\
\hline
\end{tabular}


Table 3/ Sensitivity analyses of randomised controlled trials in adults assessing effect of dietary fat intake on body weight (kg) Sensitivity analysis Effect size in $\mathbf{k g}(95 \% \mathrm{Cl})$ No of comparisons, $\mathrm{I}^{2}(\%)$

Removing trials with more attention to low fat arm $-1.42(-2.12$ to -0.73$)$ 8,38

Removing trials with dietary interventions additional to fat $-1.90(-2.49$ to -1.31$)$ 22, 69

Meta-analysis using fixed effects analysis $-1.04(-1.18$ to -0.90$)$ 27,74

Excluding single largest trial ${ }^{\star}$ $-1.65(-2.10$ to -1.21$)$ 26,69

Excluding trial without or with unclear allocation concealment $-1.10(-1.56$ to -0.65$)$ 13,59 


\section{Figures}

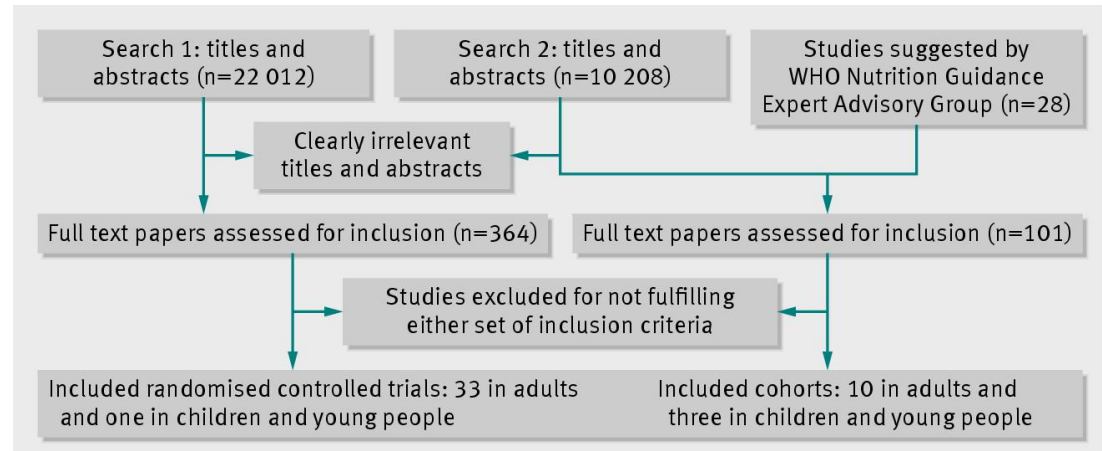

Fig 1 Flow of papers through study

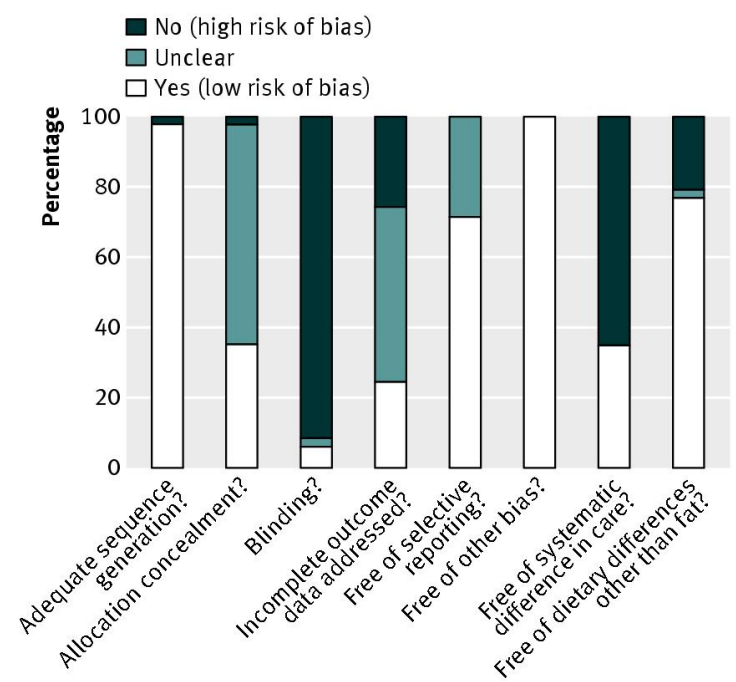

Fig 2 Quality assessment by criteria in included randomised controlled trials 


\section{Study}

\section{Difference of up to $5 \%$ energy from fat}

BDIT pilot studies (Boyd 1996) ${ }^{17}$

Bloemberg $1991^{21}$

BRIDGES (Hebert 2001) 22

German fat reduced (Seppelt 1996) ${ }^{28}$

Kentucky low fat (Anderson 1990)2930

MeDiet (Castagnetta 2006) 33

National Diet Heart Study (Open 1st) $1968^{36}$

National Diet Heart Study (Open 2nd) $1968^{36}$

WHEL (Pierce 2007) ${ }^{49}$

Subtotal $(95 \% \mathrm{Cl})$

Heterogeneity: $\tau^{2}=0.14, \chi^{2}=6.14, d f=5, P=0.29, I^{2}=19 \%$

Test for overall effect: $\mathrm{Z}=0.55, \mathrm{P}=0.58$

Difference of $5 \%$ to $<\mathbf{1 0} \%$ energy from fat

Aukland reduced fat (Ley 1999) ${ }^{16}$

beFIT $1997^{18-20}$

CARMEN $2000^{2425}$

CARMEN (metabolic syndrome substudy) $2002^{24}$

De Bont 1981 (non-obese) ${ }^{26}$

De Bont 1981 (obese) ${ }^{26}$

DEER (Stefanick 1998) (exercise, men) ${ }^{27}$

DEER (Stefanick 1998) (exercise, women) ${ }^{27}$

DEER (Stefanick 1998) (no exercise, men) ${ }^{27}$

DEER (Stefanick 1998) (no exercise, women) ${ }^{27}$

MSFAT (Van het Hof 1995) ${ }^{35}$

Rivellese et al $1994^{41}$

Swedish breast cancer $1990^{45-47}$

Women's Health Initiative (Howard 2006) ${ }^{50}$

Women's Intervention Nutrition Study (Chlebowski 1993) ${ }^{52}$

Subtotal $(95 \%$ Cl)

Heterogeneity: $\tau^{2}=1.09, \chi^{2}=66.93, \mathrm{df}=12, \mathrm{P}<0.001, \mathrm{I}^{2}=82 \%$

Test for overall effect: $Z=5.87, P<0.001$

\section{Difference of $10 \%$ to $<15 \%$ energy from fat}

Canadian diet and breast cancer prevention (Boyd 1997) ${ }^{23}$

Mastopathy diet (Boyd 1988) 32 $^{2}$

Polyp Prevention Trial $1996^{39} 40$

Women's Health Trial: Feasibility $1990^{51}$

Women's Health Tial: Feasibility Study in Minoity Populations 2

Subtotal $(95 \% \mathrm{Cl})$

Heterogeneity: $\tau^{2}=0.04, \chi^{2}=4.08, d f=3, P=0.25, I^{2}=26 \%$

Test for overall effect: $Z=7.36, P<0.001$

\section{Difference of $\geq 15 \%$ energy from fat}

Nutrition and breast health (Djuric 2002) ${ }^{37}$

Pilkington $1960^{38}$

Simon low fat breast cancer $1990^{42}$

Veterans dermatology (Black 1994) ${ }^{48}$

Subtotal $(95 \% \mathrm{Cl})$

Heterogeneity: $\tau^{2}=12.60, \chi^{2}=6.26, d f=2, P=0.04, I^{2}=68 \%$

Test for overall effect: $Z=1.56, P=0.12$

Unknown difference in \% energy from fat

Strychar $2009^{44}$

Subtotal $(95 \% \mathrm{Cl})$

Heterogeneity: Not applicable

Test for overall effect: $Z=2.69, P=0.007$

\section{Total $(95 \% \mathrm{Cl})$}

Heterogeneity: $\tau^{2}=0.57 ; \chi^{2}=104.03, d f=26, P<0.001, I^{2}=75 \%$

Test for overall effect: $Z=7.57, P<0.001$

Test for subgroup differences: $\chi^{2}=17.40, \mathrm{df}=4, \mathrm{P}=0.002, \mathrm{I}^{2}=77.0 \%$

$\frac{\text { Reduced fat intake }}{\text { Mean (SD) Total }} \quad \frac{\text { Usual fat intake }}{\text { Mean (SD) Total }}$

\begin{tabular}{ccccc}
\cline { 1 - 1 } \cline { 5 - 5 } Mean (SD) & Total & & Mean (SD) & To \\
& & & \\
$59.6(7.3)$ & 76 & $60.4(8.4)$ & 7 \\
$-0.94(2.68)$ & 39 & $0.06(1.86)$ & 40 \\
$0.1(4.85)$ & 48 & $0.5(4.07)$ & 46 \\
$70.3(7.4)$ & 35 & $71.9(10.0)$ & 3 \\
$1.06(2.49)$ & 47 & $0.44(2.68)$ & 5 \\
$-1.3(0.0)$ & 51 & $-0.6(0.0)$ & 5 \\
$-2.45(0.0)$ & 332 & $-1.93(0.0)$ & 689 \\
$-1.8(0.0)$ & 179 & $-1.2(0.0)$ & 21 \\
$74.1(19.53)$ & 1308 & $73.7(19.2)$ & 13 \\
& 2115 & & 25
\end{tabular}

$\begin{array}{lccc}-1.6(5.4) & 48 & 2.13(5.0) & 51 \\ -2.7(0.0) & 217 & 0.0(0.0) & 192 \\ -1.37(3.42) & 159 & 0.8(4.1) & 77 \\ -0.77(6.02) & 18 & 0.41(2.49) & 8 \\ -0.4(2.8) & 36 & 0.1(2.0) & 29 \\ -2.7(3.6) & 34 & -0.9(3.5) & 35 \\ -4.2(4.2) & 48 & -0.6(3.1) & 47 \\ -3.1(3.7) & 43 & -0.4(2.5) & 43 \\ -2.8(3.5) & 49 & 0.5(2.7) & 46 \\ -2.7(3.5) & 46 & 0.8(4.2) & 45 \\ 0.4(2.36) & 117 & 1.12(2.36) & 103 \\ -1.8(0.0) & 27 & -1.6(0.0) & 17 \\ -0.4(5.5) & 63 & 1.3(5.5) & 106 \\ -0.8(10.1) & 16297 & -0.1(10.1) & 25056 \\ -2.7(15.3) & 386 & 0.0(15.3) & 998 \\ & 17588 & & 26853\end{array}$

8

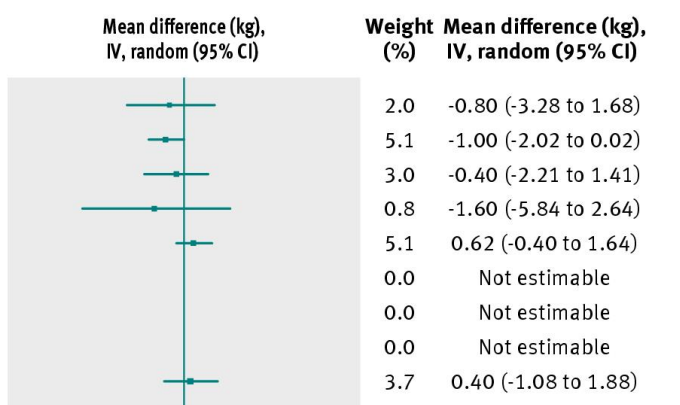

Fig 3 Effect of low fat versus usual fat diet on body weight $(\mathrm{kg})$, subgrouped by difference in percentage of energy from fat between control and reduced fat groups 